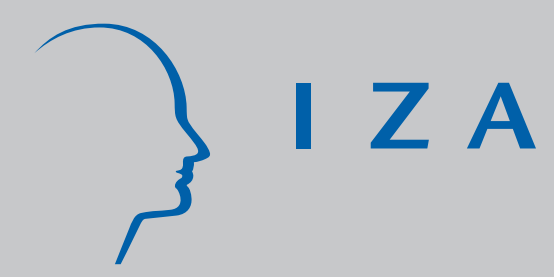

IZA DP No. 806

Multiple Equilibria and Minimum Wages in Labor Markets with Informational Frictions and Heterogeneous Production Technologies

Gerard J . van den Berg

J une 2003 


\title{
Multiple Equilibria and Minimum Wages in Labor Markets with Informational Frictions and Heterogeneous Production Technologies
}

\author{
Gerard J. van den Berg \\ Free University of Amsterdam, Tinbergen Institute, IFAU-Uppsala, \\ INSEE-CREST, CEPR and IZA Bonn
}

\author{
Discussion Paper No. 806 \\ June 2003
}

\author{
IZA \\ P.O. Box 7240 \\ D-53072 Bonn \\ Germany \\ Tel.: +49-228-3894-0 \\ Fax: +49-228-3894-210 \\ Email: iza@iza.org
}

This Discussion Paper is issued within the framework of IZA's research area Evaluation of Labor Market Policies and Projects. Any opinions expressed here are those of the author(s) and not those of the institute. Research disseminated by IZA may include views on policy, but the institute itself takes no institutional policy positions.

The Institute for the Study of Labor (IZA) in Bonn is a local and virtual international research center and a place of communication between science, politics and business. IZA is an independent, nonprofit limited liability company (Gesellschaft mit beschränkter Haftung) supported by Deutsche Post World Net. The center is associated with the University of Bonn and offers a stimulating research environment through its research networks, research support, and visitors and doctoral programs. IZA engages in (i) original and internationally competitive research in all fields of labor economics, (ii) development of policy concepts, and (iii) dissemination of research results and concepts to the interested public. The current research program deals with (1) mobility and flexibility of labor, (2) internationalization of labor markets, (3) welfare state and labor market, (4) labor markets in transition countries, (5) the future of labor, (6) evaluation of labor market policies and projects and (7) general labor economics.

IZA Discussion Papers often represent preliminary work and are circulated to encourage discussion. Citation of such a paper should account for its provisional character. A revised version may be available on the IZA website (www.iza.org) or directly from the author. 
IZA Discussion Paper No. 806

June 2003

\section{ABSTRACT}

\section{Multiple Equilibria and Minimum Wages in Labor Markets with Informational Frictions and Heterogeneous Production Technologies*}

It is often argued that a mandatory minimum wage is binding only if the wage density displays a spike at it. In this paper we analyze a model with search frictions and heterogeneous production technologies, in which imposition of a minimum wage affects wages even though, after imposition, the lowest wage in the market exceeds the minimum wage. The model has multiple equilibria as a result of the fact that the reservation wage of the unemployed and the lowest production technology in use affect each other. Imposition of a minimum wage may improve social welfare.

JEL Classification: J3, D83, J42, J6, C72

Keywords: wages, productivity, job search, unemployment, imperfect information, equilibrium, labor market policy, matching, congestion

Gerard J. van den Berg

Department of Economics

Free University of Amsterdam

De Boelelaan 1105

1081 HV Amsterdam

The Netherlands

Email: gjvdberg@xs4all.nl

\footnotetext{
${ }^{*}$ Many thanks to Randall Wright for comments that substantially improved the paper. Also thanks to two anonymous Referees, Katarina Richardson, Audra Bowlus, Jim Albrecht, Arie Kapteyn, and participants at the SED 1999 meeting and at seminars and workshops at Chicago, Bonn, Aarhus, Maastricht, and Amsterdam, for very useful comments.
} 


\section{Introduction}

The effect of a minimum wage on unemployment has been subject of a large number of empirical studies ${ }^{2}$. To provide a theoretical explanation of a zero (or negative) effect, Card and Krueger (1995) hint at monopsony models of the labor market. Monopsony power is generated by informational frictions or search frictions. ${ }^{3}$ Basically, if firms pay wages that are strictly smaller than the productivity level of the workers then they can still maintain a positive workforce and earn a profit, because it takes time for the workers to find a better paying job. The imposition of a mandatory minimum wage reduces the degree to which employers can exploit their monopsony power. In a basic equilibrium search model framework, this shifts the whole wage distribution upward, but unemployment is not necessarily affected (see Van den Berg and Ridder, 1998). In more general frameworks, unemployment decreases if the upward shift of the wage distribution induces unemployed workers to accept jobs more frequently (see Burdett and Mortensen, 1998, and Bontemps, Robin and Van den Berg, 1999) or increase their search intensity. In this context, a minimum wage can have the additional beneficial effect of driving out less productive firms (see Eckstein and Wolpin, 1990).

All of these effects concern comparative-statics results in equilibrium search models of the labor market (see below for a discussion of the literature). In this paper we examine a minimum wage effect that has not been detected before. This effect follows from the existence of multiple candidate equilibria on the labor market, in the context of informational frictions and dispersion of firms' production technologies. To understand the existence of multiple equilibria intuitively, note first of all that a wage offer by a firm must be in between the reservation wage of the unemployed and the productivity level of the firm. Then, basically, a labor market has either (1) high-productivity as well as low-productivity firms,

\footnotetext{
${ }^{2}$ See Brown, Gilroy and Kohen (1982) for a survey of research up to the early eighties and Card and Krueger (1995) for a more recent survey.

${ }^{3}$ See Boal and Ransom (1997) and Manning (2003) for recent surveys on monopsony.
} 
with unemployed workers using a low reservation wage, or (2) high-productivity firms only, with unemployed workers using a high reservation wage. In the second equilibrium, the high reservation wage acts as a binding lower bound on the set of production technologies that enable a positive profit per worker. It rules out production at a low productivity level. Now, in general (i.e., in both equilibria), part of the rent of production is distributed to the workers in the form of the wage. The resulting wage distribution for the second equilibrium dominates the wage distribution in the first equilibrium. This in turn justifies the higher reservation wage in the second equilibrium.

It is important to take into account that the job offer arrival rates for the workers may depend on the measure of active firms in the economy by way of the matching technology in the labor market. If the measure of firms decreases then the contact rate for workers may decrease as well. If this is ignored then the reservation wage of the unemployed in the second equilibrium may be overestimated.

Now suppose that the labor market is in the first equilibrium, and consider the imposition of a minimum wage exceeding the productivity level of the lowproductivity firms. The latter will go bankrupt, and the resulting equilibrium is the second equilibrium, with on average higher wages and more efficient production. If the minimum wage is subsequently abolished, the labor market may not deviate from the second equilibrium. So then a temporary imposition or increase of the minimum wage is sufficient to force the labor market from the unfavorable to the favorable equilibrium.

The empirical research on minimum wage effects generally assumes that a minimum wage is binding only if the wage density is observed to display a spike at it. This spike is thought to represent jobs with productivity at or above the minimum wage as well as below the minimum wage. The latter jobs may exist temporarily because of job protection legislation or because of the fact that factor substitution and investment take time. If a spike is absent then, by analogy to the competitive model, it is argued that workers and wages are only marginally affected by a change in the minimum wage. The analysis in the present paper 
has radically different implications. First, if the imposition of a minimum wage changes the equilibrium outcome, then the wage density in the new equilibrium does not necessarily have a spike at the lowest wage. Indeed, the lowest wage can be strictly larger than the mandatory minimum wage, even if productivity is continuously distributed across firms. Our results are thus consistent with data on repeated cross-sections showing that the minimum wage level affects the shape of the wage density even though the latter does not have a spike at the minimum wage level (see e.g. Östros, 1994, who examines Swedish data). ${ }^{4}$ Second, if there are multiple equilibria then the abolishment of the minimum wage may not affect the equilibrium. This could lead to the erroneous conclusion that the minimum wage was therefore irrelevant.

During the past decade, the theoretical and empirical analysis of equilibrium search models has become widespread (see surveys by Van den Berg, 1999, and Mortensen and Pissarides, 1999). Most of this literature builds on Burdett and Mortensen (1998) and Mortensen (1990), who develop a model with homogeneous workers and firms in which workers are allowed to search on the job, and who extend this model by introducing heterogeneity. In the homogeneous model, the possibility of on-the-job search is a sufficient condition for wage dispersion in equilibrium. In that case, job-to-job transitions are important for maintaining the workforce of a firm. The resulting models satisfy a large number of stylized facts of the labor market, particularly concerning the relations between job durations, wages, and the sizes of firms (see e.g. Ridder and Van den Berg, 1997).

In this paper we adopt the Mortensen (1990) model in which workers search on the job and and production technologies are dispersed across firms. Bowlus,

\footnotetext{
${ }^{4}$ Absence of a spike could also be the result of measurement errors in wage data. But in that case one would still expect probability mass in a small interval around the minimum wage and many wage observations below that. Absence of probability mass around the minimum wage could also be the result of wages being bargained to lie halfway a worker threshold value just below the minimum wage and a firm threshold value that is much higher, but in that case the minimum wage has no effect (and it has to be assumed that there are no firms with threshold values just above the minimum wage).
} 
Kiefer and Neumann (1995, 2001), Bowlus (1997), and Bunzel et al. (2001), amongst others, estimate this model allowing for a finite number of different firm types. They argue that in general a rather small number of firm types gives a reasonable fit to the main quantiles of the wage distribution. For expositional reasons, we mostly assume that there are two possible productivity levels. This model is sufficiently rich for our purposes, apart from the fact that we have to make the contact rates dependent on the measure of agents in the market. We show that the results also apply in the case of a continuous productivity distribution.

The above literature has not shown multiplicity of equilibrium, or for that sake the possibility that equilibrium may switch in response to policy changes. Mortensen (1990) derives properties of the equilibrium solutions. Bontemps, Robin and Van den Berg (2000) analyze a model with a continuous distribution of different production technologies. This model is able to give a perfect fit to wage data, but due to its complexity it is less amenable to a formal analysis of conditions for multiplicity of equilibrium.

The multiplicity does not depend on the assumption that firms post wages; it also occurs in wage bargaining models, like in the models of Mortensen (1999) and Acemoglu (2001). In equilibrium search and matching models, multiplicity typically reflects a coordination failure. The "eagerness" with which participants at one side of the market engage in their rent-seeking behavior depends on the "eagerness" of the participants at the other side (and on their composition), and vice versa. In this sense there is a similarity to multiplicity results in Diamond (1982), Burdett and Coles (1997), Burdett and Wright (1998), Masters (1999), and Burdett, Lagos and Wright (2002).

The outline of the paper is as follows. In Section 2 we present the model. In Section 3 we derive the candidate equilibria, we derive multiplicity in model extensions, and we demonstrate the empirical importance of multiplicity. Section 4 deals with the effects of changes in the minimum wage. Section 5 concludes. 


\section{The model framework}

Because most of the model framework is discussed in Mortensen (1990) as well as in subsequent theoretical and empirical studies, the present exposition can be brief. The model considers a labor market consisting of a continuum of workers and firms. The measure of workers is denoted by $m$, and the measure of unemployed workers by $u$. In Mortensen (1990), the measure of firms is normalized to one. Here, we must be more explicit on this. In a given steady-state equilibrium, there can be active (profitable) firms as well as non-active latent firms that may be active in another equilibrium. We assume that the total measure of firms (active or potentially active) is fixed, for example because it is determined by capital endowments, and we denote this measure by $n$.

The supply side of the model is equivalent to a standard partial job search model with on-the-job search (see Mortensen, 1986). Workers obtain wage offers, which are random drawings from the wage offer distribution $F(w)$, at a rate $\lambda_{0}$ when unemployed and $\lambda_{1}$ when employed. At this stage we do not yet specify how these depend on the measure of agents in the market. Whenever an offer arrives, the decision has to be made whether to accept it or to reject it and search further for a better offer. Firms post wage offers and they do not bargain over the wage. Layoffs accrue at the constant exogenous rate $\delta .^{5}$ The opportunity cost of employment is denoted by $b$ and is assumed to be constant across individuals and to be inclusive of unemployment benefits and search costs. We take $0<$ $\lambda_{0}, \lambda_{1}, \delta<\infty$ and $b \geq 0 .{ }^{6}$ The optimal acceptance strategy for the unemployed is then characterized by a reservation wage $\phi$ satisfying

$$
\phi=b+\left(\lambda_{0}-\lambda_{1}\right) \int_{\phi}^{\infty} \frac{1-F(w)}{\delta+\lambda_{1}(1-F(w))} d w
$$

It is not difficult to show that this equation gives a unique solution for $\phi$ given

\footnotetext{
${ }^{5}$ The separation rate $\delta$ can be interpreted to capture an idiosyncratic instantaneous large decrease in the productivity of the worker in his current job.

${ }^{6}$ For expositional reasons we restrict attention to the limiting case in which the discount rate is infinitesimally small. The results are robust with respect to this.
} 
the other variables and functions. ${ }^{7}$ Unemployed workers accept any wage offer exceeding their reservation wage, and employed workers accept any wage offer exceeding their current wage. As usual, we assume for expositional convenience that unemployed workers also accept wage offers equal to $\phi$.

Now consider flows of workers. Active firms do not offer a wage below $\phi$, so that all wage offers will be acceptable for the unemployed. Consequently, the flow from unemployment to employment is $\lambda_{0} u$. The flow from employment to unemployment is $\delta(m-u)$. In a steady state these flows are equal and the resulting rate $u / m$ of unemployed workers equals

$$
\frac{u}{m}=\frac{\delta}{\delta+\lambda_{0}}
$$

Let the distribution of wages paid to a cross-section of employees have distribution function $G$. By imposing that the steady state flows into and out of this crosssection are equal it follows that

$$
G(w)=\frac{\delta F(w)}{\delta+\lambda_{1}(1-F(w))}
$$

From the two wage distributions we derive the steady-state supply of labor $l(w \mid F)$ to an employer setting a wage $w$, where we explicitly indicate its dependence on the wages offered by other firms. Somewhat loosely, one may say that this must equal the number of workers earning $w$ in a steady state, divided by the number of firms paying $w$ in the steady state. Note that it is assumed that a firm pays the same wage to all of its employees. Let $n_{a}$ denote the measure of active firms (this is not a fundamental model determinant but rather an equilibrium outcome). As a result,

$$
l(w \mid F)=\frac{m-u}{n_{a}} \frac{\delta\left(\delta+\lambda_{1}\right)}{\left(\delta+\lambda_{1}(1-F(w))\right)^{2}}
$$

\footnotetext{
${ }^{7}$ The derivative of the left-hand side with respect to $\phi$ equals one. If $\lambda_{0} \geq \lambda_{1}$ then the derivative of the r.h.s. w.r.t. $\phi$ is negative or zero. If $\lambda_{0}<\lambda_{1}$ then the derivative of the r.h.s. w.r.t. $\phi$ is positive and uniformly smaller than one.
} 


$$
=\frac{m \delta \lambda_{0}\left(\delta+\lambda_{1}\right)}{n_{a}\left(\delta+\lambda_{0}\right)} \frac{1}{\left(\delta+\lambda_{1}(1-F(w))\right)^{2}}
$$

See Bontemps, Robin and Van den Berg (2000) for a formal analysis. The equation above only holds if $F$ does not have mass points. Further, in this equation, $w$ has of course to exceed $\phi$ (we do not consider a mandatory minimum wage until Section 4).

Now consider a firm with a flow $p$ of marginal revenue product generated by employing one worker. For convenience, we assume that $p$ does not depend on the number of employees, i.e. we assume that the production function is linear in employment. We refer to this firm as a firm of type $p$ and to $p$ as the (labor) productivity of this firm. Each firm sets a wage $w$ so as to maximize its steady-state profit flow $(p-w) l(w \mid F)$ given $F$ and given the behavior of workers.

We distinguish between two types of firms in this labor market. Firms of type $p_{2}\left(p_{1}\right)$ have a production technology that gives them a low (high) labor productivity $p_{2}\left(p_{1}\right)$, with $p_{1}>p_{2}$. It should be emphasized that this productivity level is a firm characteristic and not a worker characteristic. ${ }^{8}$ A fraction $q$ of the total measure of firms (active or potentially active) consists of type- $p_{1}$ firms, and the remaining fraction $1-q$ consists of type- $p_{2}$ firms. We take $p_{1}, p_{2}$ and $q$ (and therefore the measures both types of firms $q n$ and $(1-q) n)$ to be fixed. ${ }^{9}$ We take $p_{1}>b$ and $0<q<1$.

Mortensen (1990) derives a number of properties of any equilibrium. First of all, the equilibrium wage offer distribution $F$ has no mass point. Equivalent firms offer different wages but receive the same profit flow. In terms of total profits

\footnotetext{
${ }^{8}$ Here, one may think of a market in which individuals with a certain level of education are employable in two different occupations. If the firms' profit function is additive in occupation types then without loss of generality a single firm may employ different occupations.

${ }^{9}$ For example, these may have been determined by capital endowments. Indeed, Acemoglu and Shimer (2000) show that productivity dispersion can be explained as an equilibrium outcome by letting ex ante homogeneous firms choose their capital before production starts (see also Robin and Roux, 1999). Alternatively, productivity dispersion may be the result of differences in product market power. Mortensen (2000) provides an explanation based on the choice of match-specific capital. However, such productivity dispersion does not lead to multiple equilibria.
} 
of a firm, there is a trade-off between the profit per worker and the steady-state number of workers at the firm. A second property is that profit-maximizing wages for type- $p_{1}$ employers are larger than profit-maximizing wages for type- $p_{2}$ employers, if both types are active, and there is no gap between the corresponding parts of the support of $F$. Indeed, firms with a higher labor productivity offer higher wages, have a larger labor force and have larger profit flows than firms with lower labor productivity. A third property is that the lowest wage in the market $\underline{w}$ equals the reservation wage $\phi$ of the unemployed.

We now specify $\lambda_{0}$ and $\lambda_{1}$ as functions of the measures of active agents in the market. If the measure of active firms decreases then, on the one hand, there are less firms to be sampled by workers. On the other hand, the remaining firms will be larger (they will have larger labor forces) so they may well be easier to locate by searching workers. The values of $\lambda_{0}$ and $\lambda_{1}$ are only independent of $n_{a}$ if these effects exactly counterbalance. To proceed, we assume that the flow of contacts between workers and employers is a function $M(.,$.$) of the "effective" measure$ of searching workers and the measure of vacancies. In line with the literature, this function is called the matching function (although "contact function" would be a more appropriate name). Consider the second argument of $M(.,$.$) . All$ active firms always want to expand, as the profit per additional worker is always strictly positive. These firms always have a vacancy, and they wait passively for searching workers. Thus, the measure of vacancies equals the measure $n_{a}$ of active firms. Now consider the first argument of $M(.,$.$) . All workers always search for$ (better) jobs. The "effective" measure of searching workers may differ from the measure of searching workers $m$ because employed workers may have a different search intensity than unemployed workers. We assume that all workers' search intensities are always at their physical maximum, which depends on the worker's labor market state but does not vary across workers. Let $\alpha>0$ denote the relative search efficiency of employed workers in comparison to unemployed workers. Then the effective measure of searching workers can be written as $u+\alpha(m-u)$. It follows that we can write 


$$
\lambda_{0}=\frac{M\left(u+\alpha(m-u), n_{a}\right)}{u+\alpha(m-u)}, \quad \lambda_{1}=\frac{M\left(u+\alpha(m-u), n_{a}\right)}{u+\alpha(m-u)} \cdot \alpha
$$

so that $\alpha \equiv \lambda_{1} / \lambda_{0}$.

We assume that $M(.,$.$) displays constant returns to scale (CRS), which is$ in line with the empirical literature on matching functions for the labor market (see e.g. Mortensen and Pissarides, 1999). In particular, we adopt a CRS CobbDouglas specification,

$$
M\left(u+\alpha(m-u), n_{a}\right)=\mu \cdot(u+\alpha(m-u))^{1-\beta} n_{a}^{\beta}
$$

For ease of exposition we rule out that $\beta=1$, so that $0 \leq \beta<1$. Later on we also examine increasing and decreasing returns to scale specifications.

\section{Candidate equilibria}

In this section we show that the model of Section 2 can have multiple candidate equilibria. In one equilibrium, all active firms are type- $p_{1}$ firms, whereas in another, both types are active. The number of candidate equilibria is exhausted by a third equilibrium in which only a fraction of the type- $p_{2}$ firms is active.

We are concerned with non-cooperative steady-state equilibria. Somewhat loosely, such equilibria can be thought to consist of a reservation wage $\phi$ and a wage offer distribution $F$ such that $(i) \phi$ satisfies (1) given $F$, (ii) $F$ follows from the firms' maximizations of their own steady-state profit flows, and (iii) the job offer arrival rates satisfy (5), with $n_{a}$ being the measure of firms that make a positive profit and $u$ satisfying (2).

\subsection{Only high-productivity firms}

We start by assuming that only type- $p_{1}$ firm types are active in equilibrium. This must be verified, by checking whether in equilibrium $\phi>p_{2}$. If the latter does not hold then there is an incentive for type- $p_{2}$ firms to enter the market. We derive the equilibrium solution as follows: first derive the wage offer distribution 
for a given unknown $\phi$ and given $\lambda_{i}$. Then calculate the actual reservation wage by substituting the wage offer distribution into equation (1). Finally, substitute equations (5) for $\lambda_{i}$, and check whether the resulting $\phi$ exceeds $p_{2}$.

If only type- $p_{1}$ firms are active then we have a model with homogeneous firms. The equilibrium in such a model has been solved many times in the literature (see e.g. Burdett and Mortensen, 1998). Note that here the measure $n_{a}$ of active firms equals $q n$. We obtain that

$$
F(w)=\frac{\delta+\lambda_{1}}{\lambda_{1}}\left(1-\sqrt{\frac{p_{1}-w}{p_{1}-\phi}}\right)
$$

$F$ has support $(\phi, \bar{w})$, with $\bar{w} \in\left(\phi, p_{1}\right)$ following from $F(\bar{w})=1$. Furthermore,

$$
G(w)=\frac{\delta}{\lambda_{1}}\left(1-\sqrt{\frac{p_{1}-\phi}{p_{1}-w}}\right)
$$

By substituting (7) into (1), it follows that

$$
\phi=\frac{\left(\delta+\lambda_{1}\right)^{2} b+\left(\lambda_{0}-\lambda_{1}\right) \lambda_{1} p_{1}}{\left(\delta+\lambda_{1}\right)^{2}+\left(\lambda_{0}-\lambda_{1}\right) \lambda_{1}}
$$

There is an equilibrium in which only type- $p_{1}$ firms are active if and only if this $\phi$ satisfies $\phi>p_{2}$, which holds if and only if

$$
\left(\lambda_{0}-\lambda_{1}\right) \lambda_{1}\left(p_{1}-p_{2}\right)>\left(\delta+\lambda_{1}\right)^{2}\left(p_{2}-b\right)
$$

where, at this stage, it should be noted that $\lambda_{i} \equiv \alpha^{i} \mu(q n /(u+\alpha(m-u)))^{\beta}$ (with $i=0,1$ ), and $u$ is the equilibrium unemployment. It is straightforward to construct examples where this candidate equilibrium exists. It does not exist if both $p_{2} \geq b$ and $\alpha>1$ (so that $\lambda_{1}>\lambda_{0}$ ). This makes sense: if search in employment is more efficient than search in unemployment then an unemployed worker accepts a job with a wage equal to $b$, so then type- $p_{2}$ firms can make a positive profit. 


\subsection{High-productivity firms as well as low-productivity firms}

Now suppose that firms of both types are active in equilibrium. This must again be verified, by checking whether in equilibrium $\phi \leq p_{2}$. The equilibrium expressions follow from the equilibrium properties listed in Section 2. Note that here the measure $n_{a}$ of active firms equals $n$. The support of $F$ consists of two adjacent parts, say $(\phi, \widehat{w})$ and $(\widehat{w}, \bar{w})$. On $(\phi, \widehat{w})$,

$$
F(w)=\frac{\delta+\lambda_{1}}{\lambda_{1}}\left(1-\sqrt{\frac{p_{2}-w}{p_{2}-\phi}}\right)
$$

where $\widehat{w}$ follows from the restriction that $F(\widehat{w})=1-q$. On $(\widehat{w}, \bar{w})$,

$$
F(w)=\frac{\delta+\lambda_{1}}{\lambda_{1}}\left(1-\frac{\delta+\lambda_{1} q}{\delta+\lambda_{1}} \sqrt{\frac{p_{1}-w}{p_{1}-\widehat{w}}}\right)
$$

where $\bar{w}$ follows from $F(\bar{w})=1$.

Here, as well as in the previous subsection, the shape of $F$ reflects the market power of workers vis-à-vis employers. A low degree of search frictions for employed job seekers (i.e. a high $\lambda_{1} / \delta$ ) provides an incentive for firms to pay high wages, and a firm paying a high wage has a large labor force.

By substituting (11) and (12) into (1), it follows that

$$
\phi=\frac{\left(\delta+\lambda_{1}\right)^{2} b+\left(\lambda_{0}-\lambda_{1}\right) \lambda_{1}\left(c p_{1}+(1-c) p_{2}\right)}{\left(\delta+\lambda_{1}\right)^{2}+\left(\lambda_{0}-\lambda_{1}\right) \lambda_{1}}
$$

with $c$ defined as

$$
c=\left(\frac{\left(\delta+\lambda_{1}\right) q}{\delta+\lambda_{1} q}\right)^{2}
$$

Note that $0<c<1$ and that the denominator of $\phi$ is positive. The expression for $\phi$ is similar to the expression (9) for the homogeneous model. The only difference is that the productivity level in the homogeneous model is replaced by a weighted average of the productivities in the present model. The weights $c$ and $1-c$ reflect 
the relative importance of $p_{1}$ and $p_{2}$ for the unemployed individual. ${ }^{10}$ In general, $c$ does not equal $q$, because workers can move from low-productivity firms to high-productivity firms. The weight $c$ increases in $q$ and $\lambda_{1} / \delta$. This makes sense, as a high value of $q$ means that high-productivity jobs are abundant, while a high value of $\lambda_{1} / \delta$ means that it is relatively easy to move quickly to a job with a high productivity.

There is an equilibrium in which both types of firms are active if and only if $\phi$ in (13) satisfies $\phi \leq p_{2}$. This can be shown to hold if and only if

$$
\left(\lambda_{0}-\lambda_{1}\right) \lambda_{1} c\left(p_{1}-p_{2}\right) \leq\left(\delta+\lambda_{1}\right)^{2}\left(p_{2}-b\right)
$$

where $\lambda_{i} \equiv \alpha^{i} \mu(n /(u+\alpha(m-u)))^{\beta}$ and $u$ is the equilibrium unemployment. Again, it is straightforward to construct examples where this candidate equilibrium exists.

\subsection{High-productivity firms and a fraction of the low- productivity firms}

In the third candidate equilibrium, all type- $p_{1}$ firms and a fraction $\xi(0<\xi<1)$ of the type- $p_{2}$ firms are active. Obviously, this can only be an equilibrium if the steady-state profit flow of the active type- $p_{2}$ firms is zero, i.e. if $\phi=p_{2}$. This means that the active type- $p_{2}$ firms only employ formerly unemployed workers who accept a wage equal to their reservation wage.

To derive the equilibrium expressions we proceed as follows. The measure of active firms equals $n(q+\xi(1-q))$. Assume for the moment that the $\lambda_{i}$ are fixed constants. Replace $q$ in the equilibrium expression for $\phi$ in Subsection 3.2 by

\footnotetext{
${ }^{10}$ This can be seen from the expression for the mean wage $\mathrm{E}_{G}(w)$ earned by employed workers for a given lowest wage $\underline{w}<p_{2}$,

$$
\mathrm{E}_{G}(w)=\frac{\delta}{\delta+\lambda_{1}} \underline{w}+\frac{\lambda_{1}}{\delta+\lambda_{1}}\left(c p_{1}+(1-c) p_{2}\right)
$$

Since workers do not discount the future, $\mathrm{E}_{G}(w)$ is the expected steady-state income flow in employment for a currently unemployed worker.
} 
$q /(q+\xi(1-q)) \cdot{ }^{11}$ Subsequently, determine $\xi$ from the equation $\phi=p_{2}$. This should satisfy $\xi \in(0,1)$, with $\lambda_{i} \equiv \alpha^{i} \mu(n(q+\xi(1-q)) /(u+\alpha(m-u)))^{\beta}$ and $u$ is the equilibrium unemployment. This procedure results in

$$
\xi=\frac{q}{\delta(1-q)}\left\{-\delta-\lambda_{1}+\sqrt{\left(\lambda_{0}-\lambda_{1}\right) \lambda_{1} \frac{p_{1}-p_{2}}{p_{2}-b}}\right\}
$$

where $\lambda_{i} \equiv \alpha^{i} \mu(n(q+\xi(1-q)) /(u+\alpha(m-u)))^{\beta}$ and $u$ is the equilibrium unemployment, so that the above is an implicit equation in $\xi$. It is straightforward to construct examples where this candidate equilibrium exists with a $\xi \in(0,1)$.

\subsection{Multiplicity}

In this subsection we focus on the two candidate equilibria derived in Subsections 3.1 and 3.2. These are the most relevant for the minimum wage analyses in Section 4. Moreover, as we shall see, if these two equilibria can exist then typically the third equilibrium can also exist.

We focus on the case $\alpha<1$ (so $\lambda_{0}>\lambda_{1}$, and $\phi \geq b$ ). Theoretical search models with endogenous search intensities predict that the arrival rate for the unemployed is larger than the arrival rate for the employed (see e.g. Mortensen, 1999). Perhaps more importantly, the empirical evidence in the literature suggests that in general $\lambda_{0}>\lambda_{1} \cdot{ }^{12}$ Finally, as we shall see, $\alpha<1$ naturally leads to multiple equilibria whereas $\alpha \geq 1$ does not.

We now derive the main results on multiplicity, and we provide interpretation in the next subsection. It is useful to write $\lambda_{0}:=\lambda_{0}\left(n_{a}\right)$ to distinguish between the arrival rates in different candidate equilibria. From Subsection 3.1 , the equilibrium in which only type- $p_{1}$ firms are active exists if and only if

\footnotetext{
${ }^{11}$ This effectively amounts to imposing that the measure of type- $p_{1}$ firms equals $n q /(q+\xi(1-$ $q))$ and the measure of type- $p_{2}$ firms equals $n \xi(1-q) /(q+\xi(1-q))$; note that $\phi$ does not depend on the size of the market other than by way of the $\lambda_{i}$.

${ }^{12}$ For example, Ridder and Van den Berg (1998) estimate these parameters for a number of OECD countries, and they find that, typically, $\lambda_{0}$ is larger than $\lambda_{1}$. See also Bontemps, Robin and Van den Berg, 2000, for a discussion of empirical results in the literature.
} 
$\alpha(1-\alpha)\left(\lambda_{0}(q n)\right)^{2}\left(p_{1}-p_{2}\right)>\left(\delta+\alpha \lambda_{0}(q n)\right)^{2}\left(p_{2}-b\right)$. From Subsection 3.2, the equilibrium in which all firms are active exists if and only if $\alpha(1-\alpha)\left(\lambda_{0}(n)\right)^{2} q^{2}\left(p_{1}-\right.$ $\left.p_{2}\right)<\left(\delta+\alpha \lambda_{0}(n) q\right)^{2}\left(p_{2}-b\right)$. Thus, these two candidate equilibria both exist if and only if

$$
\frac{\alpha(1-\alpha)\left(\lambda_{0}(q n)\right)^{2}}{\left(\delta+\alpha \lambda_{0}(q n)\right)^{2}}>\frac{p_{2}-b}{p_{1}-p_{2}} \geq \frac{\alpha(1-\alpha)\left(\lambda_{0}(n)\right)^{2} q^{2}}{\left(\delta+\alpha \lambda_{0}(n) q\right)^{2}}
$$

Note that the middle term only depends on monetary flow variables whereas the left-hand and right-hand sides only depend on time rates and the fraction $q$ of high-productivity firms. Also, if $p_{1}, p_{2}$ and $b$ all change with the same percentage (e.g. in case of a technological shock) or if $\lambda_{0}, \lambda_{1}$ and $\delta$ all change with the same percentage (e.g. in case of turbulence) then the terms in the condition for multiple equilibria do not change. It should be noted that at this stage we can not preclude existence of additional equilibria.

If $\alpha=1$ then, according to (15), it is not possible that both candidate equilibria exist - in fact there exists precisely one equilibrium. ${ }^{13}$ With $\alpha<1$, the inequalities (15) imply that for any $\delta$ and $\alpha$, there are values of $p_{1}, p_{2}$ and $b$ for which both equilibria exist if and only if

$$
\lambda_{0}(q n)>q \lambda_{0}(n)
$$

Until now we have not exploited the functional form of the matching function. Intuitively, it may seem that condition (16) is always satisfied if the matching function is concave in the measure of vacancies (or active firms). This a fairly innocuous assumption. For example, it holds if the matching function $M(x, y)=x^{\gamma} y^{\beta}$ with $0 \leq \beta<1$. More specifically, if $\lambda_{0}$ does not depend on the measure of active firms (so $\beta=0$ ), then (16) is always satisfied, and it is easy to characterize when multiple equilibria occur. However, in general, the situation is more complicated than suggested here, because the equilibrium unemployment rate $u$ also depends

\footnotetext{
${ }^{13}$ In the limiting case $\alpha=0$, where the employed do not receive alternative job offers, the multiplicity disappears, as this constitutes the equilibrium where all firms offer a wage equal to the value of leisure $b$ (the "monopolistic solution"; see Diamond, 1971).
} 
on $n_{a}$. The arrival rate $\lambda_{0}\left(n_{a}\right) \equiv M\left(u+\alpha(m-u), n_{a}\right) /(u+\alpha(m-u))$ then depends on $n_{a}$ directly and indirectly by way of $u$. In Appendix 1 we prove

Proposition 1 If $\alpha<1$ and the parameter $\beta$ of the matching function satisfies

$$
\beta \leq \frac{1}{2}+\frac{1}{2} \sqrt{\alpha}
$$

then for any $\delta$ and $q$ one can always find values of $p_{1}, p_{2}$ and $b$ such that both candidate equilibria exist.

Contrary to inequality (16), the proposition gives conditions for multiplicity in terms of the underlying model parameters. The condition on $\beta$ is quite weak. For moderate values of $\alpha$, the upper bound exceeds 0.75 , which is larger than typical estimates of $\beta$ (see Petrongolo and Pissarides, 2001). In fact, the above sufficient condition on $\beta$ is not necessary.

From the results in Appendix 1 it immediately follows that if $\alpha<1$ and inequality (17) is satisfied then always at least one equilibrium exists, for all possible values of the other parameters. Also, typically, if the two candidate equilibria exist then the third equilibrium exists as well.

\subsection{Interpretation and example}

If (15) is satisfied then the unique values of the structural determinants support two different candidate equilibria, and the model does not predict which one will be realized and which one will not. This multiplicity results from the interaction between the reservation wage of the unemployed and the distribution of technologies that admit profitable production. The reservation wage $\phi$ affects the distribution of $p$ among active firms by way of the restriction that such $p$ should exceed $\phi$. Thus, $\phi$ affects the lower bound of the support of the distribution of $p$ among active firms. Conversely, the distribution of $p$ among active firms affects the reservation wage, because part of the rent of production is distributed to the workers in the form of the wage. In particular, $\phi$ depends on the expectation of $a$ monotone transformation of $p$ among active firms. If the distribution of $p$ shifts 
to the right then the wage (offer) distribution shifts to the right, and if workers search more easily while unemployed than while employed (i.e., $\lambda_{0}>\lambda_{1}$ ) then this implies a higher reservation wage: it makes sense to be more selective while unemployed.

If $\lambda_{0}=\lambda_{1}$ then search while unemployed is as effective as search while employed, and consequently the reservation wage of the unemployed is equal to the instantaneous utility flow while being unemployed, which is the opportunity cost of employment $b$. This means that there is no feedback from the productivity (or wage) distribution to the reservation wage, and the equilibrium is unique.

To see the role of the endogeneity of the job offer arrival rates, it is instructive to examine the following strongly increasing returns to scale specification for the matching function: $M\left(u+\alpha(m-u), n_{a}\right)=\mu \cdot(u+\alpha(m-u)) \cdot n_{a}$. Then there are no congestion effects: the contact arrival rate is linear in the measure of active agents at the other side of the market. Somewhat loosely, this means that the rate at which an agent contacts one specific agent at the other side of the market does not depend on the aggregate number of active agents at the other side of the market. Suppose the market is in the equilibrium with only type- $p_{1}$ firms, so $\phi>p_{2}$. If type- $p_{2}$ firms were also present then this would not affect the rate at which jobs at type- $p_{1}$ firms are offered. From the point of view of the unemployed worker, the only thing that would change is that unacceptable additional jobs are offered. This does not affect the optimal strategy, so there is only one candidate equilibrium. Technically, $\lambda_{0}(q n)=q \lambda_{0}(n)$. With CRS, there are congestion effects: the activation of type- $p_{2}$ firms decreases the rate at which jobs at type- $p_{1}$ firms are offered. ${ }^{14}$

For plausible parameter values, there are generally multiple equilibria. For example, take $\lambda_{0}(n)=0.15, \alpha=0.33, \delta=0.01, b=1000, p_{2}=1100, p_{1}=1200$, and $q=0.25$. We check for which values of $\lambda_{0}(q n)$ there are multiple equilibria.

\footnotetext{
${ }^{14}$ Although with CRS, the congestion effect for the workers is smaller than if $\lambda_{0}(q n)=\lambda_{0}(n)$. This is because an increase in the number of active firms increases the job offer arrival rate of the unemployed, which in turn decreases unemployment, and this gives a further boost to the arrival rate of the remaining unemployed.
} 
The second inequality in (15) is satisfied and so the candidate equilibrium in which both firm types are active exists. The first inequality in (15) can be rewritten as an inequality on $\lambda_{0}(q n)$. This gives $\lambda_{0}(q n) \geq 0.072$. By evaluating (5) and (6) at $q n$ and $n$, it follows that this corresponds to $\beta \leq 0.50$. Now suppose we do not pin down $p_{1}, p_{2}$ and $b$ but instead look for the highest attainable $\beta$. For $\alpha=0.33$ the proposition gives $\beta<0.79$. In fact, multiplicity occurs for values of $\beta$ as high as 0.82 , given suitable values of $p_{1}, p_{2}$ and $b$.

\subsection{Additional results and generalizations of the model specification}

\section{Discounting, capital, bargaining, matching}

We have already mentioned that multiplicity may occur in a number of important model extensions. In particular, workers and/or firms may discount the future at a rate $\rho>0$. Secondly, the firm-specific productivity may be the outcome of the optimal choice of capital by ex ante homogeneous firms before production starts. Thirdly, wages may be determined in other ways, notably by bargaining, provided that the rents of the match end up being divided between worker and employer. Fourthly, for reasons of continuity, multiplicity can also occur if the matching function displays decreasing returns to scale (DRS) or increasing returns to scale (IRS). With DRS, the high-productivity equilibrium is more attractive than in the case of CRS, and this increases the scope for multiplicity. With IRS, if $M\left(u+\alpha(m-u), n_{a}\right)=\mu \cdot(u+\alpha(m-u))^{\gamma} n_{a}^{\beta}$ with $\gamma+\beta>1$ and $0<\beta<1$ then the results in Appendix 1 can be generalized to show that multiplicity occurs for a wider range of parameter values than in the proposition for the CRS case. ${ }^{15}$ However, as we have seen, if $M\left(u+\alpha(m-u), n_{a}\right)=\mu \cdot(u+\alpha(m-u)) \cdot n_{a}$ then there is no multiplicity. Other types of matching technologies may also increase the range of parameter values for which multiplicity occurs. If larger

\footnotetext{
${ }^{15}$ In fact, the analysis is simplified considerably if we adopt this matching function with $\gamma=1$, because then condition (17) in the proposition simplifies to $\beta<1$ and this would be necessary and sufficient.
} 
firms are easier to locate or if high wages generate a high search intensity of the unemployed, then the high-productivity equilibrium is more attractive than in the case of CRS, and this increases the scope for multiplicity.

In Appendix 2 we give some results for the case $\lambda_{0}<\lambda_{1}$ (i.e., $\alpha>1$ ). In the remainder of this subsection we examine some additional extensions.

\section{General discrete and continuous distributions of firm types}

Conceptually, it is straightforward to generalize the above analysis to a finite number of firm types that is larger than two. For any possible lowest productivity level among active firms, it has to be checked whether the corresponding reservation wage is both below that level and above the highest productivity level among the non-active firms. However, if we increase the numbers of firm types, the parameter inequality that characterizes whether an equilibrium exists with all possible firm types becomes cumbersome. See the working paper version Van den Berg (2000) for results.

A large number of studies has estimated equilibrium search models for different labor markets, assuming that $p$ has a discrete distribution within the market. It can be shown that often the estimates of the structural parameters are consistent with the presence of multiple equilibria if $\beta=0$, as well as for plausible positive values of $\beta$ (note that $\beta$ is not identified from data from one steady state). Examples can be constructed from Bowlus (1997) and Bunzel et al. (2001). A given labor market may allow for additional candidate equilibria, in which currently latent firms are active. Those firms have productivity levels that are below the current reservation wage or mandatory minimum wage. It cannot be inferred empirically whether additional equilibria exist or what productivity levels those firms have, simply because we do not observe any activity at currently latent firms.

Now suppose that the distribution of $p$ is continuously distributed across firms. We denote the distribution function of $p$ across all active and non-active firms by $\Gamma_{0}(p)$. This is a structural determinant. For convenience we assume that $\Gamma_{0}$ 
has a density on the support $\left(\underline{p}_{0}, \bar{p}\right)$, with $0 \leq \underline{p}_{0}<\bar{p} \leq \infty$. We assume that $\Gamma_{0}(b)<1$ and $\mathrm{E}_{\Gamma_{0}}(p)<\infty$.

Let $\underline{p}$ denote the infimum productivity of firms which make a profit and thus are active on the market. This is of course not a structural determinant. The measure of active firms $n_{a}$ equals $\left(1-\Gamma_{0}(\underline{p})\right) n$. Let $\Gamma(p)$ denote the distribution of $p$ among active firms,

$$
\Gamma(p)=\frac{\Gamma_{0}(p)-\Gamma_{0}(\underline{p})}{1-\Gamma_{0}(\underline{p})}
$$

with $p \geq \underline{p}$.

Bontemps, Robin, and Van den Berg (2000) provide a theoretical and empirical analysis of the model with a general continuous distribution for $p$. They show amongst other things that, necessarily, $\underline{p}=\max \left\{\underline{p}_{0}, \phi\right\}$ and that $\underline{w}=\phi$. In general, the equilibrium solutions do not have explicit expressions. According to numerical examples, there is a unique equilibrium for certain structural parameter values, while there is no equilibrium for others, and there are multiple candidate equilibria for yet others. From the interpretation in the previous subsection, it is intuitively plausible that we may get multiplicity. The effect of the productivity distribution on the reservation wage works by way of the expectation of a monotone transformation of $p$, and a discrete distribution with a finite number of points of support can be approximated well by a continuous distribution, in terms of such expectations. ${ }^{16}$

\footnotetext{
${ }^{16}$ Obviously, if $\lambda_{0}=\lambda_{1}$ then there is a unique equilibrium. In the working paper version Van den Berg (2000) it is demonstrated that equilibrium is unique if $\lambda_{0}>\lambda_{1}$, the arrival rates are fixed parameters, and the continuous distribution $\Gamma_{0}$ satisfies a strong condition on the shape of its right-hand tail. Bontemps, Robin, and Van den Berg (2000) prove that there always exists at least one equilibrium if $\bar{p}<\infty$, the arrival rates are fixed parameters, and there is a mandatory minimum wage. The condition that there is a mandatory minimum wage is not necessary. If $\bar{p}=\infty$ then in specific cases there may be no equilibrium. Somewhat loosely, if $\phi$ increases then the distribution of $p$ among active firms may become much more attractive, pushing up $\phi$ even more, etc.
} 


\section{Heterogeneous unemployed workers}

So far we have assumed that workers are homogeneous, and, in particular, that the opportunity value of employment $b$ is a fixed constant. This assumption is violated if some workers enjoy leisure more than others, of if unemployment benefits are dispersed. In the working paper version Van den Berg (2000) we show that the main results also hold in models in which workers in the same labor market have different individual-specific $b$ and firms have different production technolo-

gies. Such models have been studied before by MacMinn (1980), Albrecht and Axell (1984), Mortensen (1990), and Eckstein and Wolpin (1990). The mechanism behind the multiplicity of equilibrium is the same as before, in the sense that now the reservation wage of the low- $b$ individuals acts as a lower bound on the set of production technologies that enable a positive profit. The analysis of minimum wage effects is also essentially the same as in the next section.

\subsection{Social welfare}

Consider again situations in which both candidate equilibria exist. An unemployed worker contributes $b$ to social welfare, whereas an employed worker together with his employer contributes the rent of the match, which equals the productivity level. Alternatively, they contribute the productivity level minus $b$ (the first case can occur if the non-monetary value of leisure is zero and unemployment benefits are financed externally). For expositional convenience we adopt the first case; however, the results are robust with respect to this. In the equilibrium with only type- $p_{1}$ firms, the social welfare flow $\mathcal{S}_{1}$ equals

$$
\mathcal{S}_{1}=\frac{\delta m}{\delta+\lambda_{0}(q n)} b+\frac{\lambda_{0}(q n) m}{\delta+\lambda_{0}(q n)} p_{1}-q n \cdot k_{1}
$$

Here and below, $k_{i}$ denotes the instantaneous cost flow due to the acquisition of production technology $p_{i}$. Note that the model can be extended to endogenize the choice of $p_{i}$ by assuming that the ex ante steady-state profit flow is equal for different $i$. Also note that the presence of $k_{i}>0$ implies that additional 
parameter inequalities are required to ensure that steady-state profit flows are non-negative. ${ }^{17}$ We simply assume that these are satisfied.

In the other equilibrium, the social welfare flow $\mathcal{S}_{2}$ equals

$$
\mathcal{S}_{2}=\frac{\delta m}{\delta+\lambda_{0}(n)} b+\frac{\lambda_{0}(n) m}{\delta+\lambda_{0}(n)}\left[G(\widehat{w}) p_{2}+(1-G(\widehat{w})) p_{1}\right]-q n \cdot k_{1}-(1-q) n \cdot k_{2}
$$

where $G$ denotes the cross-sectional wage distribution among workers in this equilibrium. Using equation $(3), G(\widehat{w})$ can be expressed in terms of $F(\widehat{w})$, which equals $1-q$. As a result,

$\mathcal{S}_{2}=\frac{\delta m}{\delta+\lambda_{0}(n)} b+\frac{\lambda_{0}(n) m}{\delta+\lambda_{0}(n)}\left[p_{1}-\frac{\delta(1-q)}{\delta+\alpha \lambda_{0}(n) q}\left(p_{1}-p_{2}\right)\right]-q n \cdot k_{1}-(1-q) n \cdot k_{2}$ so, for given $\lambda_{0}, \mathcal{S}_{2}$ increases in $\alpha$ and in $q$. This makes sense. If $\alpha$ is large then workers move quickly from type- $p_{2}$ jobs to type- $p_{1}$ jobs. In the words of Acemoglu and Shimer (2000), equilibrium is more efficient because workers can achieve a more efficient allocation by sampling more firms. If $q$ is large then there are not many type- $p_{2}$ jobs in the first place.

If $\lambda_{0}(n)=\lambda_{0}(q n)$ then the equilibrium with only type- $p_{1}$ firms is to be preferred, since employed workers are on average more productive in this equilibrium, whereas unemployment is the same in both equilibria. ${ }^{18}$ However, with $\lambda_{0}(n)>\lambda_{0}(q n)$, the unemployment rate is higher in the equilibrium with only type- $p_{1}$ firms, and this decreases social welfare. In general,

$$
\begin{gathered}
\frac{\delta+\lambda_{0}(n)}{\delta m}\left(\mathcal{S}_{1}-\mathcal{S}_{2}\right)= \\
\frac{\lambda_{0}(n)(1-q)}{\delta+\alpha \lambda_{0}(n) q}\left(p_{1}-p_{2}\right)-\frac{p_{1}-b}{\delta+\lambda_{0}(q n)}\left(\lambda_{0}(n)-\lambda_{0}(q n)\right)+\frac{\delta+\lambda_{0}(n)}{\delta m}(1-q) n \cdot k_{2}
\end{gathered}
$$

The first term on the right-hand side represents the productivity gain for the type- $p_{1}$ equilibrium. The second term represents the loss due to increased unemployment. The third term represents the gain because of increased returns

\footnotetext{
${ }^{17}$ For example, if $\lambda_{0}=\lambda_{1}$ and $b<p_{2}$ then $\phi<p_{2}$, but the steady-state profit flow of type- $p_{2}$ firms is non-negative iff $p_{2}-b>k_{2}(n / m)\left(\delta+\lambda_{0}\right)^{2} /\left(\delta \lambda_{0}\right)$.

${ }^{18}$ Note that here it is important that we assume constant marginal product of labor. Concave production functions make the equilibrium with only type- $p_{1}$ firms less attractive.
} 
to investment when the firm size is increased. There do not seem to be transparent conditions on the structural parameters under which the sum is always positive. However, for reasonable parameter values, the sum is positive, even if $k_{2}=0$. Consider the example of Subsection 3.5 with $k_{i}=0$. With both types of firms active, the mean social welfare flow $\mathcal{S}_{2} / m$ equals 1156 . Recall that the equilibrium with only high productivity firms exists if $\lambda_{0}(q n) \geq 0.072$. Consider the equilibrium with only type- $p_{1}$ firms. Within the range of admissible values of $\lambda_{0}(q n)$, the lowest social welfare and the highest unemployment rate are attained if $\lambda_{0}(q n)=0.072$. This gives $u / m=0.12$ and $\mathcal{S}_{1} / m=1176$. This social welfare is still higher than $\mathcal{S}_{2}$ despite the fact that unemployment has almost doubled. If $\lambda_{0}(q n)>0.072$ then $\mathcal{S}_{1}$ is even higher; if $\lambda_{0}(q n)=\lambda_{0}(n)=0.15$ then $\mathcal{S}_{1} / m=1188$.

\section{A minimum wage}

In this section we focus on markets with multiple candidate equilibria. That is, we assume that (15) holds, which implies that $\lambda_{0}>\lambda_{1}$ and $b<p_{2}$. Let $\phi_{1}$ and $\phi_{2}$ denote the reservation wages in the equilibrium in which only type- $p_{1}$ firms are active and in the equilibrium in which all firms are active, respectively. We call these equilibria type-1 and type-2, respectively. Now suppose that the labor market is in the type-2 equilibrium, and suppose that a mandatory minimum wage $w_{L}$ is imposed. We assume full coverage of this minimum wage. We can distinguish between five cases depending on the relative value of $w_{L}$.

(A). If $w_{L} \leq \phi_{2}$ then this does not have any effect on the equilibrium outcome.

(B). If $\phi_{2}<w_{L}<p_{2}$ then the equilibrium is still of type 2. However, $w_{L}$ replaces $\phi_{2}$ as the lowest wage in the market. The market power of workers increases at the expense of the firms' monopsony power. As a result, the whole wage (offer) distribution shifts upwards. ${ }^{19}$

\footnotetext{
${ }^{19}$ The equilibrium outcomes (11) and (12) are still valid, provided that $\phi$ is replaced by $w_{L}$.
} 
(C). If $p_{2} \leq w_{L}<\phi_{1}$ then type- $p_{2}$ firms cannot operate profitably anymore, and the type-2 equilibrium is replaced by the type- 1 equilibrium. However, the outcome of the latter equilibrium is not affected in any way by $w_{L}$ since it is smaller than $\phi_{1}$. As a result, the imposition of $w_{L}$ induces a shift in the equilibrium, but the value of $w_{L}$ itself does not affect the new equilibrium outcomes. The minimum wage is strictly smaller than the lowest wage in the market, and consequently the wage (offer) density does not display a spike at it.

(D). If $\phi_{1} \leq w_{L}<p_{1}$ then again the type-2 equilibrium is replaced by the type-1 equilibrium, but now $w_{L}$ affects the outcome of the latter equilibrium since it is the lowest wage in the market. The outcome in case of a homogeneous model with $\underline{w}=w_{L}$ has been analyzed extensively in Van den Berg and Ridder (1998).

(E). If $w_{L} \geq p_{1}$ then type- $p_{1}$ and type- $p_{2}$ firms cannot operate profitably, and there is no production.

Obviously, the most interesting cases above are $(C)$ and $(D)$, because then the minimum wage induces a shift to the type- 1 equilibrium. ${ }^{20}$ The social welfare effect $^{21}$ of this shift is smaller than the value of $\mathcal{S}_{1}-\mathcal{S}_{2}$ in the previous subsection. Most importantly, this value does not take account of the costs of destruction of type- $p_{2}$ firms, notably the costs of investment in type- $p_{2}$ capital that was made before imposition of $w_{L}$. We therefore have to subtract $(1-q) n k_{2}$ from $\mathcal{S}_{1}-\mathcal{S}_{2}$. The value of $\mathcal{S}_{1}-\mathcal{S}_{2}$ also does not take account of the short-term increase in unemployment of workers who were employed at type- $p_{2}$ firms. The dynamics of unemployment and the size of this effect are extremely difficult to calculate. Whether the imposition of $w_{L}$ increases social welfare depends on the model parameters. An equilibrium shift is not Pareto-improving when it entails a loss for the owners of type- $p_{2}$ firms. ${ }^{22}$

\footnotetext{
${ }^{20}$ The effects in $(B),(C)$ and $(D)$ are consistent with a number of stylized facts (see Card and Krueger, 1995). In general, an increase in the minimum wage decreases wage variation and has a positive effect on wages above it.

${ }^{21}$ In practice, the minimum wage level may not be determined by maximization of social welfare. Sobel (1999) convincingly argues that the relative strength of interest groups in the political process is an important determinant.

${ }^{22}$ If the labor market consists of a number of separate labor markets each with its own highest
} 
Now let us examine the effect of abolition of the minimum wage after it has been imposed. In $(A)$, nothing changes. In $(B),(D)$ and $(E)$, the equilibrium outcomes do change. In $(B)$ and $(D)$, the set of active firms does not change, but the wage distribution shifts toward lower wages. The equilibrium in $(B)$ returns to the equilibrium with outcomes that are equal to those before imposition of $w_{L}$. In $(C)$, the equilibrium outcome does not change, meaning that the temporary imposition of $w_{L}$ has established a permanent shift from the type-2 to the type-1 equilibrium.

Of course, when multiple equilibria are possible, any change in labor market policy that raises the reservation wage could potentially move the economy from the bad to the good equilibrium. Alternatives to the imposition of a minimum wage are an increase of the opportunity cost of employment $b$ and the imposition of a tax on firms.

Let us return to the effects of the imposition of $w_{L}$ in $(C)$. From the fact that the minimum wage is strictly smaller than the lowest wage in the market, a casual observer may induce that the minimum wage is not "binding" and is thus irrelevant. Indeed, he may be strengthened in this belief in the case of an abolition of the minimum wage, since the latter does not affect the equilibrium.

It is important to stress that the above results are not due to the assumption that $p$ can only attain two values. Recall from Subsection 3.4 that multiple equilibria are possible if $p$ has a continuous distribution or a discrete distribution with more than two points of support. In the model with a continuously distributed $p$, the imposition of a minimum wage in between the two reservation wages that are associated with the two equilibria ensures that one of the equilibria cannot exist anymore, but it does not affect the outcome of the other equilibrium. This corresponds to case $(C)$ above. ${ }^{23}$

level of $p$, then the imposition of a minimum wage that exceeds the highest possible $p$ within a particular market causes all individuals associated with that market to become permanently (or structurally) unemployed. This justifies a policy in which minimum wages are sector-specific and occupation-specific.

${ }^{23}$ It can be shown that similar results arise in models with match-specific productivity het- 
It is often argued that a spike in the wage density at the minimum wage indicates that the minimum wage has an effect on the wage density, whereas the absence of such a spike indicates that the minimum wage is irrelevant. The above results question the universal validity of such a view. Interestingly, wage data from European countries often do not display a spike at the minimum wage even though there is typically full compliance (see evidence in Östros, 1994, Koning, Ridder and Van den Berg, 1995, Van den Berg and Ridder, 1998, Bunzel et al., 2001, and Bontemps, Robin and Van den Berg, 2000). ${ }^{24}$

\section{Conclusion}

The mutual dependence of the reservation wage of the unemployed and the lowest profitable productivity level can generate multiplicity of equilibrium. From estimates from the literature on structural estimation of equilibrium search models it follows that multiplicity is an empirically relevant phenomenon. The results remain valid under a number of model extensions. They imply that a minimum wage policy can be fruitfully applied to single out the desirable equilibrium. In such a case, the resulting minimum wage may wrongfully appear to be irrelevant, as its value can be strictly smaller than the lowest wage in the market.

erogeneity and wage bargaining, like the Flinn and Heckman (1982) and Flinn (1999) model.

${ }^{24}$ Note that our model does not rule out the presence of a spike at $w_{L}$. In case $(B)$ above, the wage (offer) density displays a spike at $w_{L}$ if the latter is only marginally lower than $p_{2}$. In the latter case, all type- $p_{2}$ firms are active, and they are all forced to pay a wage in between $w_{L}$ and $p_{2}$. A likewise situation occurs in case $(D)$ above, if $w_{L}$ is only marginally lower than $p_{1}$. Bontemps, Robin and Van den Berg (2000) show that such a "congestion" spike in the wage density at $w_{L}$ can also be generated if $p$ is continuously distributed and fixed production costs are zero. 


\section{References}

Acemoglu, D., "Good jobs versus bad jobs", Journal of Labor Economics 19 (2001), 1-22.

Acemoglu, D. and R. Shimer, "Wage and technology dispersion", Review of Economic Studies 67 (2000), 585-608.

Albrecht, J.W. and B. Axell, "An equilibrium model of search unemployment", Journal of Political Economy 92 (1984), 824-840.

Boal, W.M. and M.R. Ransom, "Monopsony in the labor market", Journal of Economic Literature 35 (1997), 86-112.

Bontemps, C., J.M. Robin, and G.J. van den Berg, "An empirical equilibrium job search model with search on the job and heterogeneous workers and firms", International Economic Review 40 (1999), 1039-1074.

Bontemps, C., J.M. Robin, and G.J. van den Berg, "Equilibrium search with continuous productivity dispersion: theory and non-parametric estimation", International Economic Review 41 (2000), 305-358.

Bowlus, A.J., "A search interpretation of male-female wage differentials", Journal of Labor Economics 15 (1997), 625-657.

Bowlus, A.J., N.M. Kiefer, and G.R. Neumann, "Estimation of equilibrium wage distributions with heterogeneity", Journal of Applied Econometrics 10 (1995), S119-S131.

Bowlus, A.J., N.M. Kiefer, and G.R. Neumann, "Equilibrium search models and the transition from school to work", International Economic Review 42 (2001), $317-343$.

Brown, C., C. Gilroy, and A. Kohen, "The effect of the minimum wage on employment and unemployment", Journal of Economic Literature 20 (1982), 487-528.

Bunzel, H., B.J. Christensen, P. Jensen, N.M. Kiefer, L. Korsholm, L. Muus, G.R. Neumann, and M. Rosholm, "Specification and estimation of equilibrium search models", Review of Economic Dynamics 4 (2001), 90-126. 
Burdett, K. and M.G. Coles, "Marriage and class", Quarterly Journal of Economics 112 (1997), 141-168.

Burdett, K., R. Lagos, and R. Wright, "Unemployment, inequality, and crime", Working paper, University of Pennsylvania, 2002.

Burdett, K. and D.T. Mortensen, "Wage differentials, employer size, and unemployment", International Economic Review 39 (1998), 257-273.

Burdett, K. and R. Wright, "Two-sided search with nontransferable utility", Review of Economic Dynamics 1 (1998), 220-245.

Card, D. and A.B. Krueger, Myth and measurement (Princeton: Princeton University Press, 1995).

Diamond, P.A., "A model of price adjustment", Journal of Economic Theory 3 (1971), 156-168.

Diamond, P.A., "Aggregate demand management in search equilibrium", Journal of Political Economy 90 (1982), 881-894.

Eckstein, Z. and K.I. Wolpin, "Estimating a market equilibrium search model from panel data on individuals", Econometrica 58 (1990), 783-808.

Flinn, C.J., "Minimum wage effects on labor market outcomes under search with bargaining", Working paper, New York University, 1999.

Flinn, C.J. and J.J. Heckman, "New methods for analyzing structural models of labor force dynamics", Journal of Econometrics 18 (1982), 115-168.

Koning, P., G. Ridder, and G.J. van den Berg, "Structural and frictional unemployment in an equilibrium search model with heterogeneous agents", Journal of Applied Econometrics 10 (1995), S133-S151.

MacMinn, R.D., "Job search and the labor dropout problem reconsidered", Quarterly Journal of Economics 95 (1980), 69-87.

Manning, A., Monopsony in Motion (Princeton: Princeton University Press, 2003). 
Masters, A.M., "Wage posting in two-sided search and the minimum wage", International Economic Review 40 (1999), 809-826.

Mortensen, D.T., "Job search and labor market analysis", in O. Ashenfelter and R. Layard, eds., Handbook of Labor Economics (Amsterdam: North-Holland, 1986).

Mortensen, D.T., "Equilibrium wage distributions: a synthesis", in J. Hartog et al., eds., Panel data and labour market studies (Amsterdam: North-Holland, 1990).

Mortensen, D.T., "Modeling matched job-worker flows", Working paper, Northwestern University, 1999.

Mortensen, D.T., "Equilibrium unemployment with wage posting: Burdett-Mortensen meet Pissarides", in H. Bunzel et al., eds., Panel data and structural labour market models (Amsterdam: North-Holland, 2000).

Mortensen, D.T. and C.A. Pissarides, "New developments in models of search in the labor market", in O. Ashenfelter and D. Card, eds., Handbook of Labor Economics, Volume III (Amsterdam: North-Holland, 1999).

Östros, T., "Do minimum wages matter? The case of Swedish mining and manufacturing", in B. Holmlund, editor, Pay, Productivity, and Policy (Stockholm: FIEF, 1994).

Petrongolo, B. and C.A. Pissarides, "Looking into the black box: a survey of the matching function", Journal of Economic Literature 39 (2001), 390-431.

Ridder, G. and G.J. van den Berg, "Empirical equilibrium search models", in D.M. Kreps and K.F. Wallis, eds., Advances in Economics and Econometrics: Theory and Applications (Cambridge: Cambridge University Press, 1997).

Ridder, G. and G.J. van den Berg, "Estimating measures of labor market imperfection for five OECD countries, using aggregate data in an equilibrium search framework", Working paper, Free University Amsterdam, 1998.

Robin, J.M. and S. Roux, "Balanced or random matching: an equilibrium search 
model with endogenous capital and two-sided search", Working paper, LEAINRA, 1999.

Sobel, R.S., "Theory and evidence on the political economy of the minimum wage", Journal of Political Economy 107 (1999), 761-785.

Van den Berg, G.J., "Empirical inference with equilibrium search models of the labor market", Economic Journal 109 (1999), F283-F306.

Van den Berg, G.J., "Multiple equilibria and minimum wages in labor markets with informational frictions and heterogeneous production technologies", Working paper, Free University Amsterdam, 2000.

Van den Berg, G.J. and G. Ridder, "An empirical equilibrium search model of the labor market", Econometrica 66 (1998), 1183-1221. 


\section{Appendix}

\section{Proof of Proposition 1.}

From Section 2,

$$
\frac{u\left(n_{a}\right)}{m}=\frac{\delta}{\delta+\lambda_{0}\left(n_{a}\right)}
$$

By substituting (19) into (5) and using (6), we obtain a relation that can be written as the inverse of the function $\lambda_{0}\left(n_{a}\right)$ if $\beta>0$,

$$
n_{a}=\lambda_{0}^{\frac{1}{\beta}} \mu^{-\frac{1}{\beta}} m\left[\alpha+(1-\alpha) \frac{\delta}{\delta+\lambda_{0}}\right]
$$

This function is increasing. The derivative of $n_{a}$ with respect to $\lambda_{0}$ is proportional to $x^{\frac{1}{\beta}-1}(1+x)^{-2}\left[\alpha x^{2}+(1+\alpha-\beta+\alpha \beta) x+1\right]$, with $x=\lambda_{0} / \delta$. The term in square brackets is positive for all $x \geq 0$. As a result, $\lambda_{0}$ increases in $n_{a}$.

The condition (16) holds for all $0<q<1$ iff the inverse function $n_{a}\left(\lambda_{0}\right)$ satisfies

$$
\frac{n_{a}\left(\lambda_{0}\right)}{n}<\frac{\lambda_{0}}{\lambda_{0}(n)}
$$

for all $0<\lambda_{0}<\lambda_{0}(n)$, where $\lambda_{0}$ is the argument of the function $n_{a}($.$) , and n$ and $\lambda_{0}(n)$ are fixed constants. We first consider the case $\beta>0$. Equation (20) can be rewritten as

$$
\frac{n_{a}}{n}=\left(\frac{\lambda_{0}}{\lambda_{0}(n)}\right)^{\frac{1}{\beta}} \frac{\alpha+(1-\alpha) \frac{\delta}{\delta+\lambda_{0}}}{\alpha+(1-\alpha) \frac{\delta}{\delta+\lambda_{0}(n)}}
$$

Therefore, $n_{a} / n<\lambda_{0} / \lambda_{0}(n)$ iff

$$
\frac{\lambda_{0}^{\frac{1}{\beta}-1}}{\delta+\lambda_{0}}\left(\delta+\alpha \lambda_{0}\right)<\frac{\lambda_{0}(n)^{\frac{1}{\beta}-1}}{\delta+\lambda_{0}(n)}\left(\delta+\alpha \lambda_{0}(n)\right)
$$

We already know that $\lambda_{0}\left(n_{a}\right)<\lambda_{0}(n)$, so if the function $x^{\frac{1}{\beta}-1}(\delta+\alpha x) /(\delta+x)$ strictly increases in $x$ for $x \in\left(0, \lambda_{0}(n)\right]$, then the inequality (21) is true for all $\lambda_{0} \in\left(0, \lambda_{0}(n)\right)$ (i.e. for all $\left.q \in(0,1)\right)$. The derivative of this function with respect to $x$ is proportional to 


$$
\alpha(1-\beta) x^{2}+\delta(1+\alpha-2 \beta) x+\delta^{2}(1-\beta)
$$

Clearly, the values of this expression are positive for every $x \geq 0$ if the second coefficient $\delta(1+\alpha-2 \beta)$ is non-negative. This gives the sufficient condition $0<\beta \leq(1+\alpha) / 2$. Expression (22) is a second-degree polynomial in $x$. After some elaboration it follows that its values are positive on $\mathbb{R}$ iff $(1-\sqrt{\alpha}) / 2<\beta<$ $(1+\sqrt{\alpha}) / 2$, and its values are positive on $\mathbb{R}$ except at one point iff $\beta=(1-\sqrt{\alpha}) / 2$ or $\beta=(1+\sqrt{\alpha}) / 2$. This gives the second sufficient condition: $(1-\sqrt{\alpha}) / 2 \leq$ $\beta \leq(1+\sqrt{\alpha}) / 2$. Together, the two conditions result in $0<\beta \leq(1+\sqrt{\alpha}) / 2$. In fact, the latter gives a complete characterization of the parameter values for which (22) is positive for all $x \geq 0$ except possibly for one $x$ value, given that $0<\alpha, \beta<1$. Finally, if $\beta=0$ the $\lambda_{0}$ does not depend on $n_{a}$, so (16) is trivially satisfied for every $0<q<1$.

\section{Higher job offer arrival rate in employment.}

Let $\lambda_{0}<\lambda_{1}$, i.e., $\alpha>1$. Then, the higher the wages, the more important it is to leave unemployment as quickly as possible, so the lower the reservation wage. From the intuition behind the multiplicity in the case $\lambda_{0}>\lambda_{1}$ it is obvious that multiplicity is not to be expected in this reverse case. Indeed, by using the results in Appendix 1 in conjunction with inequalities (15), it can be demonstrated that there are no multiple equilibria for any $\alpha>1$ and $0 \leq \beta<1 .^{25}$ For certain ranges of parameter values, neither of the two candidate equilibria we considered exists (see footnote 25), but the third candidate equilibrium where only a fraction of the low-productivity firms are active exists. Somewhat loosely, if all firms of both firm types are active then the reservation wage gets too high, while if only high-productivity firms are active then the reservation wage gets too low.

\footnotetext{
${ }^{25}$ In this case, inequality (16) is always satisfied, so that the negative number on the righthand side of (15) is always larger than the negative number on the left-hand side.
} 


\section{IZA Discussion Papers}

\begin{tabular}{|c|c|c|c|c|}
\hline No. & Author(s) & Title & Area & Date \\
\hline 792 & $\begin{array}{l}\text { L. Borghans } \\
\text { B. ter Weel }\end{array}$ & $\begin{array}{l}\text { What Happens When Agent T Gets a } \\
\text { Computer? The Labor Market Impact of Cost } \\
\text { Efficient Computer Adoption }\end{array}$ & 5 & $06 / 03$ \\
\hline 793 & T. Palokangas & $\begin{array}{l}\text { Foreign Direct Investment, Labour Market } \\
\text { Regulation and Self-Interested Governments }\end{array}$ & 3 & $06 / 03$ \\
\hline 794 & $\begin{array}{l}\text { P. Frijters } \\
\text { M. A. Shields } \\
\text { S. Wheatley Price }\end{array}$ & $\begin{array}{l}\text { Investigating the Quitting Decision of Nurses: } \\
\text { Panel Data Evidence from the British National } \\
\text { Health Service }\end{array}$ & 1 & $06 / 03$ \\
\hline 795 & B. T. Hirsch & $\begin{array}{l}\text { Reconsidering Union Wage Effects: Surveying } \\
\text { New Evidence on an Old Topic }\end{array}$ & 3 & $06 / 03$ \\
\hline 796 & P. Apps & Gender, Time Use and Models of the Household & 5 & $06 / 03$ \\
\hline 797 & $\begin{array}{l}\text { E. Bratberg } \\
\varnothing . \text { A. Nilsen } \\
\text { K. Vaage }\end{array}$ & $\begin{array}{l}\text { Assessing Changes in Intergenerational } \\
\text { Earnings Mobility }\end{array}$ & 2 & $06 / 03$ \\
\hline 798 & $\begin{array}{l}\text { J. J. Heckman } \\
\text { J. A. Smith }\end{array}$ & $\begin{array}{l}\text { The Determinants of Participation in a Social } \\
\text { Program: Evidence from a Prototypical Job } \\
\text { Training Program }\end{array}$ & 6 & $06 / 03$ \\
\hline 799 & R. A. Hart & $\begin{array}{l}\text { General Human Capital and Employment } \\
\text { Adjustment in the Great Depression: } \\
\text { Apprentices and Journeymen in UK Engineering }\end{array}$ & 2 & $06 / 03$ \\
\hline 800 & $\begin{array}{l}\text { T. Beissinger } \\
\text { C. Knoppik }\end{array}$ & $\begin{array}{l}\text { Sind Nominallöhne starr? Neuere Evidenz und } \\
\text { wirtschaftspolitische Implikationen }\end{array}$ & 7 & $06 / 03$ \\
\hline 801 & A. Launov & $\begin{array}{l}\text { A Study of the Austrian Labor Market Dynamics } \\
\text { Using a Model of Search Equilibrium }\end{array}$ & 2 & $06 / 03$ \\
\hline 802 & $\begin{array}{l}\text { H. Antecol } \\
\text { P. Kuhn } \\
\text { S. J. Trejo }\end{array}$ & $\begin{array}{l}\text { Assimilation via Prices or Quantities? Labor } \\
\text { Market Institutions and Immigrant Earnings } \\
\text { Growth in Australia, Canada, and the United } \\
\text { States }\end{array}$ & 1 & $06 / 03$ \\
\hline 803 & R. Lalive & Social Interactions in Unemployment & 3 & $06 / 03$ \\
\hline 804 & J. H. Abbring & Dynamic Econometric Program Evaluation & 6 & $06 / 03$ \\
\hline 805 & $\begin{array}{l}\text { G. J. van den Berg } \\
\text { A. van Vuuren }\end{array}$ & The Effect of Search Frictions on Wages & 6 & $06 / 03$ \\
\hline 806 & G. J. van den Berg & $\begin{array}{l}\text { Multiple Equilibria and Minimum Wages in Labor } \\
\text { Markets with Informational Frictions and } \\
\text { Heterogeneous Production Technologies }\end{array}$ & 6 & $06 / 03$ \\
\hline
\end{tabular}

An updated list of IZA Discussion Papers is available on the center's homepage www.iza.org. 